\title{
Assessing Physical Activity and its Relationship to Cardiovascular Risk Factors: NHANES 2003-2006
}

\author{
Amy Luke ${ }^{* \dagger}$, Lara R Dugas ${ }^{\dagger}$, Ramon A Durazo-Arvizu ${ }^{\dagger}$, Guichan $\mathrm{CaO}^{\dagger}$ and Richard S Cooper ${ }^{\dagger}$
}

\begin{abstract}
Background: Levels of physical activity (PA) in the general population are difficult to characterize. Historically measurement has been based on self-report, which can be subject to bias. PA monitor use has created opportunities to improve surveillance and analytic research on activity and health. The aims of the current study were to investigate the associations between objectively measured PA and cardiovascular disease risk factors and obesity.
\end{abstract}

Methods: Data on PA from accelerometers, demographics, blood pressure, plasma glucose and lipids, self-reported hypertension and diabetes were obtained for adults, ages 20-65, in the NHANES surveys, 2003-2006. Outcomes were assessed as levels of moderate and vigorous activity, percentage of participants meeting recommended guidelines, and the correlations between activity and cardiovascular risk factors. Accelerometry data were available on 3,370 adults. Based on standard algorithms, activity levels were extremely low in all age-gender-race/ethnic groups, with an average of only 1 bout of vigorous activity lasting longer than 1 minute/day.

Results: Men spent 35 minutes in moderate activity/day, women 21 minutes; $>75 \%$ of this activity was accumulated in 1-minute bouts. Levels of activity declined sharply after age 50 in all groups. Negative associations were observed between minutes of combined moderate and vigorous activity and systolic blood pressure, blood glucose, diabetes, hypertension, body mass index and obesity, and a positive association was seen with HDL-cholesterol (all $P \leq 0.03$ ), suggesting valid rank ordering of participants by activity level.

Conclusion: The magnitude of the gap between self-report and accelerometry activity must be a result of either a vast social acceptability bias in reporting or inaccurate measurement with accelerometry. Therefore, due to the low validity of self reported PA data for epidemiologic research, it is pertinent to encourage the use of valid, objective methods to assess PA.

\section{Background}

The population burden attributable to cardiovascular disease (CVD) has evolved rapidly over the last 50 years. Vigorous efforts to improve levels of smoking, hypercholesterolemia and uncontrolled hypertension have contributed significantly to the $75 \%$ reduction in CVD mortality in the US since 1968 [1,2]. This improvement in lifestyle continues and several goals for Healthy People 2010 for heart disease and stroke risk factors have already been met [3]. As is well recognized, however, significant adverse trends in obesity and diabetes have emerged and threaten to erode these gains [4]. The new

\footnotetext{
* Correspondence: aluke@lumc.edu

+ Contributed equally

Department of Preventive Medicine and Epidemiology, Loyola University

Stritch School of Medicine, 2160 S. $1^{\text {st }}$ Ave Maywood, IL, 60153, USA
}

urgency attached to the prevention of obesity and its sequelae has furthermore heightened interest in potential strategies that can limit age-related weight gain [5]. Unfortunately, despite the relatively straightforward nature of the energy equation, balancing calorie intake with expenditure has become difficult for large segments of the population in the current obesigenic environment. In an attempt to address the obesity epidemic, considerable emphasis has therefore been placed on surveillance of physical activity and the initiation of campaigns to enhance leisure activity [6,7]. These strategies depend on accurate information about patterns and levels of energy expenditure in the general population.

In contrast to the "classic" CVD risk factors, until recently assessment of physical activity in large population studies has relied on self-reported questionnaires

\section{Biomed Central}


while direct measurement has been feasible only in relatively small validation studies [8,9]. Self-report of behaviors such as alcohol intake, diet and physical activity are notoriously unreliable, being subject to both random and systematic reporting bias [10-12]. Development of improved physical activity monitors, i.e., accelerometers, has now made it possible to measure activity patterns objectively in free-living individuals [13-15]. Doubly labeled water (DLW), a non-invasive method of indirect calorimetry [16], has also been applied on a limited scale to field research $[17,18]$, however, it remains prohibitively expensive for most large studies, and accelerometers are likely to be the most widespread technique that will be used for the foreseeable future.

In the 2003-2006 NHANES surveys participants wore an accelerometer for 7 consecutive days. In this analysis we examine the patterns of physical activity in the 3,370 individuals between 20 and 65 years with adequate quality data and non-debilitating illnesses and assess the relationship between activity and CVD risk factors and obesity.

\section{Methods}

Data from NHANES 2003-2006 were used in these analyses. Using a complex, multistage probability sampling design, NHANES recruited a representative sample of the total civilian non-institutionalized population, 2 months and older, in the United States. Briefly, NHANES participants perform an at-home interview and, approximately two weeks later, a clinic examination at a mobile examination center (MEC). The examination lasts approximately 3-4 hours and site-specific error is minimized by standardizing all data-collection methods [19]. All participants provide informed consent for both the at-home interview and MEC examination and the US Department of Health and Human Service approved the study. During NHANES 2003-2006, a total of 20,470 individuals were interviewed and examined (all ages). Of 7,501 individuals between the ages of 20 and 65, 4,463 individuals wore the activity monitor for a minimum of 4 valid wear days. There were 1,093 adults excluded for one of the following reasons: missing BMI data $(n=31)$, pregnant at time of examination $(n=240)$, self-reported race/ethnicity other than non-Hispanic white, non-Hispanic black or Mexican American ( $\mathrm{n}=343$ ), or selfreported chronic health condition that might have impacted physical activity levels, such as congestive heart failure, stroke or emphysema $(n=542)$. Thus, the analytical sample included 3,370 adults between 20 and 65 years of age.

Weight $(\mathrm{kg})$ and height $(\mathrm{m})$ were measured according to standard procedures and used to calculate body mass index (BMI, $\mathrm{kg} / \mathrm{m}^{2}$ ). Brachial SBP and DBP measurements were made during a single examination and following standard procedures; the average value for up to three measurements was used [20].

Blood was drawn following an overnight fast and processed according to standard procedures [21]; plasma glucose and lipids concentrations were measured. Plasma glucose was assessed and triglycerides and HDLcholesterol were measured in serum (Roche Diagnostics, Indianapolis, IN), while levels of LDL-cholesterol were calculated using the Friedewald formula [21].

Physical activity monitors (Actigraph model 7164; Actigraph LLC; Fort Walton Beach, FL) were placed on all ambulatory participants six years and older [22]. The Actigraph records vertical accelerations as "counts" representing the relative intensity of each movement [23]. The monitor was worn over the right hip; participants were asked to wear the monitor while awake and remove it for swimming or bathing [15]. Data were summarized in 1-minute epochs for 7 days.

For the purpose of our analyses, we included accelerometer data from 3,370 healthy individuals, 20-65 years of age, who met our minimum wear time criteria, as described below. Each participant was required to achieve a minimum of 10 hrs of monitor wear on four or more days. Wear time was determined by subtracting non-wear time from $24 \mathrm{hr}$, while non-wear time was defined as an interval of $\geq 60$ consecutive minutes with zero activity counts allowing for intervals of 1-2 minutes of relatively low activity counts, i.e., 1-100 counts [15]. The average number of valid wear days was 5.97 for men and 5.94 for women.

We defined moderate and vigorous physical activity cut-points for adults using previously published recommendations [24], as described by Troiano [15]. Briefly, cut-points allow the conversion of accelerometer counts into estimates of activity intensity, i.e., moderate or vigorous, using weighted averages. The cut-point was 2020 counts/min for moderate activity and 5999 counts/min for vigorous; these were used to estimate the total number of minutes per day spent in each activity level. We present physical activity data as the total time in minutes accumulated in either 1 - or 10-minute intervals of moderate, vigorous or moderate plus vigorous activity, as well as activity counts per minute (ct/min). Following prior conventions, we allowed for up to 2 minutes of below threshold count activity before considering the bout to be ended [15]. For these analyses, therefore, the continuous measure of "counts over time" was converted into "bouts" and these became the unit of analysis.

As a form of sensitivity analysis, we repeated the estimates of time spent in moderate or vigorous activity using cut-points which progressively reduced the counts per minute down to a minimum of $30 \%$ of the pre-set standards described above [15]. 
Participants were identified as diabetic if they selfreported having the condition or were taking insulin or oral hypoglycemic medications. Participants were identified as hypertensive if they were taking anti-hypertensive medication or their systolic blood pressure (SBP) was $\geq 140$ or diastolic blood pressure (DBP) was $\geq 90$. We used standardized BMI cut-points to categorize participants as either overweight (BMI $\geq 25$ and $<30 \mathrm{~kg} / \mathrm{m}^{2}$ ) or obese $\left(\mathrm{BMI} \geq 30 \mathrm{~kg} / \mathrm{m}^{2}\right)[22]$.

\section{Statistical Methods}

Data are presented as the total time accumulated in either 1 - or 10-minute bouts of activity level, mean counts per minute and mean wear time. Weighted means and standard errors are computed for each of the continuous variables of interest, and proportions with standard errors are reported for the categorical variables by sex and race/ethnicity, accounting for the complex sampling scheme used by NHANES. Plasma glucose concentrations were adjusted using the fasting sampling weights included in the NHANES dataset. Partial correlation coefficients were computed for each of the physical activity measures with well-established CVD risk factors, BMI, overweight and obesity accounting for age, gender and race/ethnicity. Standardized coefficients were used to express change in the dependent variable per standard deviation in the independent variables. Summary statistics and correlation coefficients were calculated using SUDAAN (v.9, Research Triangle Park, NC), and Stata SE (v.11, College Station, TX).

\section{Results}

The characteristics of the 3,370 participants' ages 20-65 years are presented in Table 1 . The mean age of Mexican-American participants was somewhat lower than for the other racial/ethnic groups (i.e., 36 years vs. 42 for whites and 39 for blacks). As anticipated, overweight and obesity were common in all groups, with a substantially higher prevalence in blacks. In addition, blacks had higher blood pressures and lower total cholesterol and LDL-C levels. Diabetes prevalence, unadjusted for age, was higher in blacks $(8.0 \%)$ than either whites $(3.6 \%)$ or Mexican Americans (5.0\%), as was hypertension prevalence (42.9\% vs. $22.4 \%$ and $12.5 \%$, respectively).

Physical activity was summarized as the mean number of counts per minute (cts/min) and in the categories of moderate or vigorous, presented in 1-minute and 10minute bouts (Table 2). The average counts were higher among men than women (393 vs. $321 \mathrm{ct} / \mathrm{min}$ ), and highest among Mexican-American men and women. As anticipated, activity declined sharply after age 50 (Figure $1)$. Vigorous activity was recorded very infrequently; no gender-race groups had $\geq 1$ bout of vigorous activity per day that lasted at least 10 minutes (Table 2). Even vigorous activity bouts of 1 minute were rare, ranging from 0.4/day among Mexican American women to 1.5/ day among white men. Daily moderate activity was recorded in 32 to 41 bouts of 1 -minute duration in men, and 18 to 201 -minute bouts in women. Given the potential for artifact, the significance of 1-minute bouts of activity is difficult to interpret. The most stable estimate of activity patterns may therefore be the number of minutes per day spent in 10-minute bouts of activity. This measure ranged from a high of 10.3 minutes per day of moderate plus vigorous activity among MexicanAmerican men to a low of 5.0 minutes among MexicanAmerican women, with a population average of $6.6 \mathrm{~min}$ utes per day. Furthermore, over $66 \%$ of men and $68 \%$ of women did not accumulate a single 10-minute bout of moderate or vigorous activity on any of the days.

Previous national prevalence estimates of activity patterns have come exclusively from questionnaires on discrete behaviors and have suggested that relatively large proportions of the population meet current physical activity guidelines $[8,25,26]$. In contradiction, activity as measured by activity monitors demonstrated that guidelines are rarely being met. Thus, only $0.2 \%$ of women and $0.4 \%$ of men in the NHANES sample would have met current guidelines requiring a minimum of approximately two 10-minute blocks of moderate activity per day [6]. While more individuals accumulated greater amounts of total moderate activity, the overwhelming majority of this time was accounted for by 1-minute bouts (i.e., 75\%); the time spent in longer bouts declined rapidly (Figure 2). Across the entire 6-day average period of recording, only $14 \%$ had a single block lasting 20 minutes.

Quantification of physical activity using accelerometry depends critically on the number of counts per minute used as the cut-point defining moderate or vigorous activity. Accelerometers can be well calibrated for walking or running but may miss other forms of body motion thereby underestimating intensity. As a sensitivity analysis we therefore reduced the number of counts required to qualify as moderate/vigorous activity in a stepwise fashion from $80 \%$ of the laboratory-validated standard down to $30 \%$, and repeated the analyses above. Current guidelines of two 10-minute blocks of moderate activity per day were met by $1.9 \%$ of the population with the threshold reduced to $80 \%$ of the standard and $29.5 \%$ when the threshold was only $30 \%$ of the standard. Most importantly, the majority of time in activity ( 90\%) was still spent in 1 minute bouts, suggesting sustained fitness-inducing exercise continued to be rare even at this much reduced threshold of counts per minute.

As a means of evaluating the internal validity of the monitoring procedure we examined the relationship 
Table 1 Characteristics of Participants by Gender-Race/Ethnic Groups (mean, SE) - NHANES 2003-2006, ages 20-65 y ( $n=3,370)$

\begin{tabular}{|c|c|c|c|c|c|c|c|c|}
\hline \multirow[t]{2}{*}{ Variable } & \multicolumn{2}{|c|}{$\begin{array}{l}\text { White } \\
(\mathrm{N}=1763)\end{array}$} & \multicolumn{2}{|c|}{$\begin{array}{c}\text { Black } \\
(\mathrm{N}=761)\end{array}$} & \multicolumn{2}{|c|}{$\begin{array}{l}\text { Mexican American } \\
\quad(\mathrm{N}=846)\end{array}$} & \multicolumn{2}{|c|}{$\begin{array}{c}\text { Total } \\
(\mathrm{N}=3370)\end{array}$} \\
\hline & Mean & SE & Mean & SE & Mean & SE & Mean & SE \\
\hline Male (\%) & 51.8 & 1.1 & 47.5 & 2.0 & 56.9 & 1.5 & 51.7 & 1.0 \\
\hline Age (y) & 41.7 & 0.4 & 39.0 & 0.4 & 36.2 & 0.6 & 40.8 & 0.4 \\
\hline Height (cm) & 171.6 & 0.2 & 169.8 & 0.4 & 164.9 & 0.3 & 170.7 & 0.2 \\
\hline Weight (kg) & 82.3 & 0.6 & 85.9 & 1.2 & 77.1 & 0.8 & 82.2 & 0.5 \\
\hline Body Mass Index & 27.9 & 0.2 & 29.8 & 0.4 & 28.3 & 0.3 & 28.2 & 0.2 \\
\hline Overweight (\%) & 32.9 & 1.1 & 33.5 & 2.1 & 40.1 & 1.7 & 33.7 & 1.1 \\
\hline Obese (\%) & 29.9 & 1.5 & 42.9 & 2.4 & 31.4 & 1.9 & 31.7 & 1.3 \\
\hline Hypertensive (\%) & 22.4 & 1.3 & 30.0 & 2.1 & 12.5 & 1.7 & 22.4 & 1.1 \\
\hline Diabetic (\%) & 3.6 & 0.5 & 8.0 & 1.1 & 5.0 & 0.8 & 4.3 & 0.5 \\
\hline $\mathrm{SBP}(\mathrm{mmHg})$ & 119.5 & 0.5 & 123.2 & 0.8 & 117.7 & 0.6 & 119.8 & 0.5 \\
\hline $\mathrm{DBP}(\mathrm{mmHg})$ & 72.3 & 0.3 & 72.5 & 0.5 & 69.6 & 0.5 & 72.0 & 0.3 \\
\hline Total Cholesterol (mg/dL) & 200.3 & 1.1 & 191.7 & 1.5 & 196.8 & 1.5 & 198.8 & 0.8 \\
\hline HDL-cholesterol (mg/dL) & 54.5 & 0.4 & 56.7 & 1.0 & 50.1 & 0.5 & 54.3 & 0.3 \\
\hline LDL-cholesterol (mg/dL) & 110.6 & 1.6 & 107.6 & 1.9 & 114.0 & 1.9 & 110.6 & 1.2 \\
\hline Triglyceride (mg/dL) & 131.3 & 3.2 & 116.1 & 5.4 & 147.1 & 9.9 & 131.0 & 2.9 \\
\hline Plasma Glucose (mg/dL)* & 99.1 & 1.0 & 102.1 & 2.0 & 104.0 & 1.9 & 99.9 & 0.9 \\
\hline
\end{tabular}

*Fasting sampling weights were used for plasma glucose concentrations. Plasma glucose sample sizes: $\mathrm{n}=771$ white, $\mathrm{n}=306$ black, $\mathrm{n}=370 \mathrm{Mexican}$ American, $\mathrm{n}=1447$ total sample.

between activity measures and primary cardiovascular risk factors. In a combined analysis, with adjustment for age, gender and race/ethnicity, both activity counts per minute and number of minutes in 1-minute bouts were significantly negatively associated with SBP, blood sugar, hypertension and diabetes, while activity measures were positively associated with HDL-cholesterol (Tables 3 \&4). Table 4 presents the change in risk factor based on a standard deviation change in the activity measure; as a proportion of the mean for the given risk factor, the largest effect was seen for HDL-C, followed by glucose. In Table 4, the association with hypertension and diabetes is further summarized as the change in odds ratio; for hypertension the odds were $20 \%$ lower, and for diabetes $35 \%$ lower, with one standard deviation increase in activity. After removing the effect of BMI and age, a negative association remained for plasma glucose in the total sample and the majority of sub-groups (Table 5). Negative associations were also seen for diabetes, hypertension and HDL-cholesterol, although less consistently. Blood pressure was unrelated to activity counts or time spent in moderate activity in any of the separate genderrace/ethnicity groups; this finding may be due in part to the fact that treated hypertensives were not excluded. In

Table 2 Physical Activity Monitor Measures by Gender-Race/Ethnic Groups (mean, SE)* - NHANES 2003-2006, ages 20-65 y $(n=3,370)$

\begin{tabular}{|c|c|c|c|c|c|c|c|c|c|c|c|c|c|c|c|c|}
\hline \multirow[t]{3}{*}{ Variable } & \multicolumn{8}{|c|}{ Male } & \multicolumn{8}{|c|}{ Female } \\
\hline & \multicolumn{2}{|c|}{$\begin{array}{c}\text { White } \\
(\mathrm{N}=926)\end{array}$} & \multicolumn{2}{|c|}{$\begin{array}{c}\text { Black } \\
(\mathrm{N}=386)\end{array}$} & \multicolumn{2}{|c|}{$\begin{array}{l}\text { Mexican } \\
\text { American } \\
(\mathrm{N}=463)\end{array}$} & \multicolumn{2}{|c|}{$\begin{array}{l}\text { Total } \\
(\mathrm{N}= \\
1775)\end{array}$} & \multicolumn{2}{|c|}{$\begin{array}{l}\text { White } \\
(\mathrm{N}=837)\end{array}$} & \multicolumn{2}{|c|}{$\begin{array}{l}\text { Black } \\
\text { (375) }\end{array}$} & \multicolumn{2}{|c|}{$\begin{array}{l}\text { Mexican } \\
\text { American } \\
(\mathrm{N}=383)\end{array}$} & \multicolumn{2}{|c|}{$\begin{array}{l}\text { Total } \\
(\mathrm{N}= \\
1595)\end{array}$} \\
\hline & Mean & SE & Mean & SE & Mean & SE & Mean & SE & Mean & SE & Mean & SE & Mean & SE & Mean & SE \\
\hline Mean Counts per min & 383.6 & 5.0 & 374.4 & 8.7 & 466.4 & 9.7 & 392.7 & 4.3 & 324.7 & 4.1 & 297.9 & 6.6 & 328.1 & 5.6 & 321.0 & 3.5 \\
\hline Mean Wear Time (hr/d) & 14.6 & 0.1 & 14.9 & 0.1 & 14.3 & 0.1 & 14.6 & 0.1 & 14.2 & 0.1 & 14.3 & 0.1 & 14.0 & 0.1 & 14.2 & 0.1 \\
\hline Mod Activity (min/d in 1-min bouts) & 33.2 & 0.9 & 31.8 & 1.4 & 40.9 & 1.5 & 34.1 & 0.8 & 20.3 & 0.7 & 18.0 & 1.3 & 18.7 & 0.9 & 19.9 & 0.7 \\
\hline Vig Activity (min/d in 1-min bouts) & 1.5 & 0.2 & 1.5 & 0.3 & 1.3 & 0.3 & 1.5 & 0.1 & 1.3 & 0.1 & 0.6 & 0.1 & 0.4 & 0.1 & 1.1 & 0.1 \\
\hline Mod \& Vig (min/d in 1-min bouts) & 34.7 & 0.9 & 33.4 & 1.4 & 42.1 & 1.5 & 35.6 & 0.8 & 21.6 & 0.8 & 18.5 & 1.3 & 19.1 & 0.9 & 21.0 & 0.7 \\
\hline Mod Activity (min/d in 10-min bouts) & 7.0 & 0.5 & 7.5 & 0.8 & 8.9 & 0.6 & 7.4 & 0.4 & 5.3 & 0.5 & 4.7 & 0.8 & 4.5 & 0.4 & 5.2 & 0.4 \\
\hline Vig Activity (min/d in 10-min bouts) & 0.8 & 0.2 & 0.7 & 0.3 & 0.6 & 0.2 & 0.8 & 0.1 & 1.0 & 0.1 & 0.4 & 0.1 & 0.1 & 0.04 & 0.8 & 0.1 \\
\hline Mod \& Vig (min/d in 10-min bouts) & 8.7 & 0.6 & 9.2 & 0.9 & 10.3 & 0.6 & 9.1 & 0.5 & 6.9 & 0.6 & 5.3 & 0.9 & 5.0 & 0.4 & 6.6 & 0.5 \\
\hline
\end{tabular}

${ }^{*}$ Age-adjusted by year 2000 US population.

Abbreviations: Mod, moderate; Vig, vigorous. 


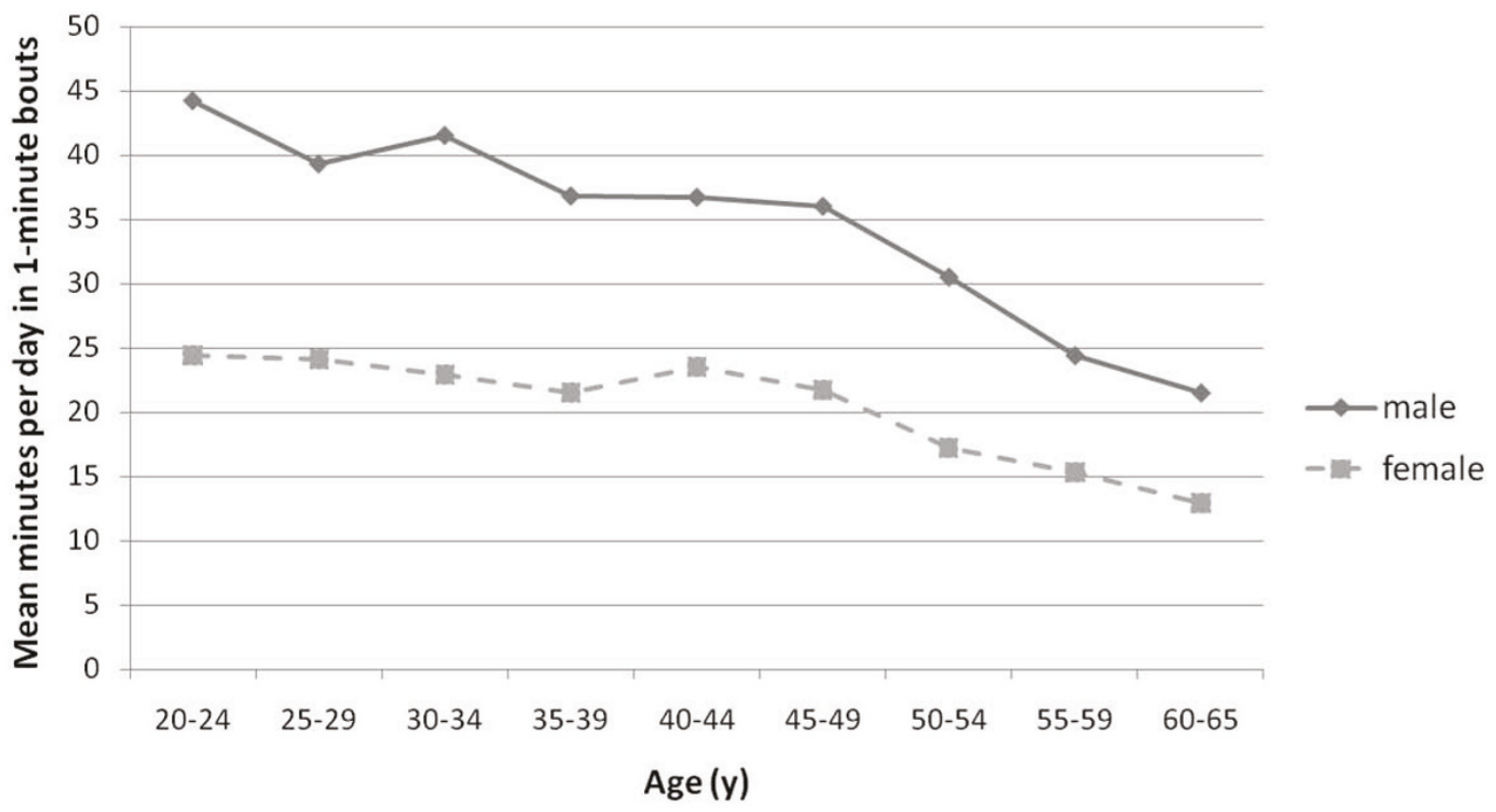

Figure 1 Mean number of minutes per day of moderate plus vigorous activity combined in 1-minute bouts by 5-year age groups NHANES 2003-2006 $(n=3,370)$.

analyses that did not include BMI these associations were roughly $30-50 \%$ larger (data not shown), indicating the substantial confounding of the activity-risk factor association from BMI.

Activity measures generated by the monitor were also examined for association with relative weight (Table 6); for brevity only moderate activity was included given the virtual absence of vigorous activity. Statistically significant negative associations with BMI were seen in each gender-race/ethnicity group, with the exception of activity counts per minute for black women, and both measures for Mexican-American women. The association with overweight was not consistent, and the nominal relationship was positive and significant in the total sample, albeit weak in magnitude. On the other hand, obesity was negatively associated in all sub-groups for at least one exposure measure, again with the exception of Mexican-American women. The contrasting results in overweight and obesity could in part reflect the fact that mean BMIs were in the overweight range. Likewise, the amount of moderate and vigorous activity in MexicanAmerican women was the lowest of the sub-groups and the sample size was modest.

\section{Discussion}

These findings from a large representative sample add a new dimension to our understanding of the patterns and consequences of physical activity in the US population.
The estimates of both vigorous and moderate activity were extremely low, and contrast dramatically with those obtained by self-report [8,25-27]. Vigorous activity lasting even 1 minute was only observed in $2 \%$ of any of the gender-race/ethnic groups and a 10-minute episode of moderate activity - the intensity obtained by walking up stairs - was recorded in only one third of the participants on any day of monitoring. The overall pattern observed among population sub-groups was, however, consistent with expectations. Mexican-American men were somewhat more active than blacks or whites, which might be attributable to physically demanding occupations, while among women whites appeared to be slightly more active than either blacks or Mexican Americans, possibly reflecting leisure time activity. Activity declined sharply with age; after 60 only $\sim 15$ minutes of moderate activity was recorded among men and 10 minutes among women per day. Despite the low mean levels a highly significant association was observed between activity level and all the major metabolic risk factors for CVD confirming that the measurements were valid and the effects sufficiently large to confer physiologic consequences.

The major finding from these analyses is the demonstration that population estimates of activity levels from surveys by questionnaire are markedly at variance with those obtained by objective measurements. As the only source available from past surveys, questionnaires have been used in analytic research and have informed public 


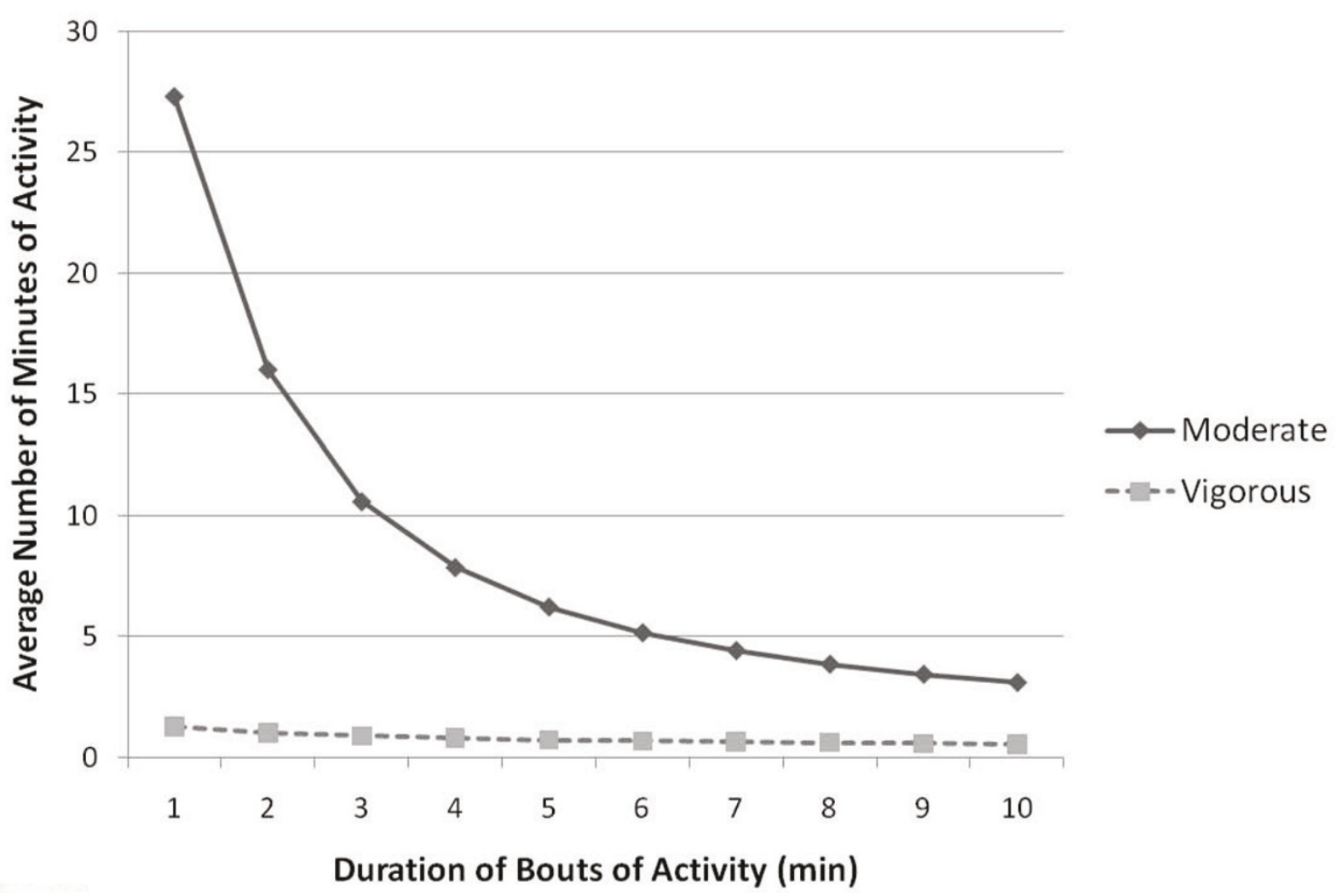

Figure 2 Number of minutes accumulated in continuous bouts of moderate or vigorous activity lasting from 1 to 10 minutes, NHANES 2003-2006, $(n=3370)$. The number of daily bouts was determined by averaging all bouts of the specified duration that were accumulated over valid wear days (i.e., number of bouts accumulated on all valid wear days/number of valid wear days; average valid wear days $=5.95)$

policy for the last 50 years. If the data presented here are correct, a re-evaluation of the conclusions from much of this literature would be required. For example, based on national survey data it was assumed in Healthy People 2010 that 23 percent of adults engaged in vigorous activity of more than 20 minutes per episode at least 3 times per week at the beginning of this decade [3]. However, in the NHANES data presented here, $<1$ percent of the population achieved this level of expenditure. Likewise, current guidelines recommend 150 minutes of moderate or 75 minutes of vigorous activity per week for adults [6]. Only $0.3 \%$, or 10 of the 3,370 individuals in this sample, achieved that level. This result is in stark contradiction to a recent report using self-reported "usual occupational/domestic activity" in a subset of the same 2003-2006 NHANES participants where $42 \%$ of persons with a mean age of 45 met current guidelines [28]; precision of this self-reported activity measure was apparently low, however, since it was unassociated with CVD risk factors. The findings of this

Table 3 Partial Correlation Coefficients Between Physical Activity Monitor Measures and Cardiovascular Disease Risk Factors* (P-value) - NHANES 2003-2006, ages 20-65 y $(\mathrm{n}=3168)$

\begin{tabular}{lccccccc}
\hline & $\begin{array}{c}\text { Systolic } \\
\text { BP }\end{array}$ & $\begin{array}{c}\text { Diastolic } \\
\text { BP }\end{array}$ & $\begin{array}{c}\text { Total } \\
\text { Cholesterol }\end{array}$ & $\begin{array}{c}\text { HDL- } \\
\text { cholesterol }\end{array}$ & $\begin{array}{c}\text { Plasma } \\
\text { Glucose }^{* *}\end{array}$ & Hypertension Diabetes \\
\hline Activity Counts per min & -0.02 & -0.02 & 0.0076 & 0.12 & -0.07 & -0.09 & -0.07 \\
& $(0.21)$ & $(0.36)$ & $(0.67)$ & $(<.0001)$ & $(0.01)$ & $(<.0001)$ & $(<.0001)$ \\
& -0.04 & -0.01 & -0.00099 & 0.11 & -0.08 & -0.07 & -0.08 \\
$\begin{array}{l}\text { Mod \& Vig Activity (min in 1-min } \\
\text { bouts) }\end{array}$ & $(0.03)$ & $(0.44)$ & $(0.96)$ & $(<.0001)$ & $(<0.001)$ & $(<.0001)$ & $(<.0001)$ \\
& & & & & &
\end{tabular}

*Adjusted for age, sex, race/ethnicity and body mass index.

** Plasma glucose concentration adjusted by fasting sampling weights; plasma glucose sample sizes: $n=771$ white, $n=306$ black, $n=370$ Mexican American, $\mathrm{n}=1447$ total sample. 
Table 4 Change in Risk Factor per Standard Deviation Change in Physical Activity* NHANES 2003-2006, ages 20-65 y ( $n=3,168)$

\begin{tabular}{|c|c|c|c|c|c|c|c|}
\hline Variable & $\begin{array}{l}\text { Systolic BP } \\
\text { (mmHg) }\end{array}$ & $\begin{array}{l}\text { Diastolic BP } \\
(\mathrm{mmHg})\end{array}$ & $\begin{array}{c}\text { Total } \\
\text { Cholesterol } \\
(\mathrm{mg} / \mathrm{dL})\end{array}$ & $\begin{array}{c}\text { HDL- } \\
\text { cholesterol } \\
(\mathrm{mg} / \mathrm{dL})\end{array}$ & $\begin{array}{c}\text { Plasma } \\
\text { Glucose }^{* *}(\mathrm{mg} / \\
\mathrm{dL})\end{array}$ & $\begin{array}{l}\text { Hypertension**** } \\
\text { OR }\end{array}$ & $\begin{array}{l}\text { Diabetes*** } \\
\text { OR }\end{array}$ \\
\hline Mean Counts per min & -0.68 & -0.34 & 0.20 & 1.56 & -1.48 & 0.78 & 0.64 \\
\hline $\begin{array}{l}\text { Mod \& Vig Activity (min/d } \\
\text { in 1-min bouts) }\end{array}$ & -0.74 & -0.07 & -0.21 & 1.49 & -1.85 & 0.81 & 0.50 \\
\hline
\end{tabular}

*Adjusted for age, sex, race/ethnicity and body mass index.

** Plasma glucose concentration adjusted by fasting sampling weights; plasma glucose sample size: $\mathrm{n}=1447$ total sample.

***Odds ratio per standard deviation change in physical activity.

recent report are not atypical as current trends based on questionnaires suggest that a large proportion of the population engages in recreational activity; these trends, however, could well be biased by a social desirability effect $[6,29,30]$.

Is the large scale downward shift of the magnitude described here a plausible assessment of activity patterns in the US population? On the surface the discrepancy between questionnaire and measured activity exceeds reasonable expectation. The only measure of validity available from the NHANES survey itself was replication of the risk factor associations. An extensive literature from observational studies and trials supports the association between exercise and CVD risk factors [31-33],

Table 5 Partial Correlation Coefficients (P-value) Between Physical Activity Monitor Measures and Cardiovascular Disease Risk Factors* by Gender-Race/Ethnic Groups - NHANES 2003-2006, ages 20-65 y (n = 3168)

\begin{tabular}{|c|c|c|c|c|c|c|c|}
\hline & $\begin{array}{l}\text { Systolic } \\
\text { BP }\end{array}$ & $\begin{array}{l}\text { Diastolic } \\
\text { BP }\end{array}$ & $\begin{array}{l}\text { Total } \\
\text { Cholesterol }\end{array}$ & $\begin{array}{l}\text { HDL- } \\
\text { cholesterol }\end{array}$ & $\begin{array}{l}\text { Plasma } \\
\text { Glucose }\end{array}$ & Hypertension & Diabetes \\
\hline \multicolumn{8}{|l|}{ White Males ( $n=896)$} \\
\hline Activity Counts per min & $\begin{array}{l}-0.05 \\
(0.17)\end{array}$ & $\begin{array}{l}-0.04 \\
(0.28)\end{array}$ & $\begin{array}{l}-0.001 \\
(0.99)\end{array}$ & $\begin{array}{l}0.18 \\
(<0.001)\end{array}$ & $\begin{array}{l}-0.06 \\
(0.21)\end{array}$ & $\begin{array}{l}-0.13 \\
(<0.001)\end{array}$ & $\begin{array}{l}-0.10 \\
(0.003)\end{array}$ \\
\hline $\begin{array}{l}\text { Mod \& Vig Activity (min in 1-min } \\
\text { bouts) }\end{array}$ & $\begin{array}{l}-0.08 \\
(0.01)\end{array}$ & $\begin{array}{l}-0.02 \\
(0.50)\end{array}$ & $\begin{array}{l}-0.002 \\
(0.95)\end{array}$ & $\begin{array}{l}0.12 \\
(<0.001)\end{array}$ & $\begin{array}{l}-0.05 \\
(0.34)\end{array}$ & $\begin{array}{l}-0.11 \\
(0.001)\end{array}$ & $\begin{array}{l}-0.11 \\
(0.001)\end{array}$ \\
\hline \multicolumn{8}{|l|}{ Black Males $(n=360)$} \\
\hline Activity Counts per min & $\begin{array}{l}-0.02 \\
(0.74)\end{array}$ & $\begin{array}{l}0.06 \\
(0.22)\end{array}$ & $\begin{array}{l}0.02 \\
(0.67)\end{array}$ & $\begin{array}{l}0.05 \\
(0.36)\end{array}$ & $\begin{array}{l}-0.16 \\
(0.05)\end{array}$ & $\begin{array}{l}0.09 \\
(0.11)\end{array}$ & $\begin{array}{l}-0.08 \\
(0.14)\end{array}$ \\
\hline $\begin{array}{l}\text { Mod \& Vig Activity (min in 1-min } \\
\text { bouts) }\end{array}$ & $\begin{array}{l}-0.05 \\
(0.37)\end{array}$ & $\begin{array}{l}0.05 \\
(0.33)\end{array}$ & $\begin{array}{l}0.007 \\
(0.89)\end{array}$ & $\begin{array}{l}0.11 \\
(0.03)\end{array}$ & $\begin{array}{l}-0.14 \\
(0.08)\end{array}$ & $\begin{array}{l}0.07 \\
(0.22)\end{array}$ & $\begin{array}{l}-0.10 \\
(0.05)\end{array}$ \\
\hline \multicolumn{8}{|c|}{ Mexican-American Males $(n=440)$} \\
\hline Activity Counts per min & $\begin{array}{l}0.048 \\
(0.313)\end{array}$ & $\begin{array}{l}-0.03 \\
(0.59)\end{array}$ & $\begin{array}{l}-0.002 \\
(0.97)\end{array}$ & $\begin{array}{l}0.02 \\
(0.66)\end{array}$ & $\begin{array}{l}0.01 \\
(0.85)\end{array}$ & $\begin{array}{l}-0.01 \\
(0.81)\end{array}$ & $\begin{array}{l}-0.01 \\
(0.78)\end{array}$ \\
\hline $\begin{array}{l}\text { Mod \& Vig Activity (min in 1-min } \\
\text { bouts) }\end{array}$ & $\begin{array}{l}0.068 \\
(0.153)\end{array}$ & $\begin{array}{l}-0.07 \\
(0.14)\end{array}$ & $\begin{array}{l}-0.02 \\
(0.64)\end{array}$ & $\begin{array}{l}0.01 \\
(0.81)\end{array}$ & $\begin{array}{l}-0.05 \\
(0.51)\end{array}$ & $\begin{array}{l}0.02 \\
(0.74)\end{array}$ & $\begin{array}{l}-0.02 \\
(0.72)\end{array}$ \\
\hline \multicolumn{8}{|l|}{ White Females ( $n=784$ ) } \\
\hline Activity Counts per min & $\begin{array}{l}-0.03 \\
(0.44)\end{array}$ & $\begin{array}{l}0.01 \\
(0.76)\end{array}$ & $\begin{array}{l}0.02 \\
(0.53)\end{array}$ & $\begin{array}{l}0.11 \\
(0.002)\end{array}$ & $\begin{array}{l}-0.05 \\
(0.31)\end{array}$ & $\begin{array}{l}-0.11 \\
(0.003)\end{array}$ & $\begin{array}{l}-0.04 \\
(0.33)\end{array}$ \\
\hline $\begin{array}{l}\text { Mod \& Vig Activity (min in 1-min } \\
\text { bouts) }\end{array}$ & $\begin{array}{l}-0.04 \\
(0.27)\end{array}$ & $\begin{array}{l}0.03 \\
(0.44)\end{array}$ & $\begin{array}{l}-0.02 \\
(0.67)\end{array}$ & $\begin{array}{l}0.11 \\
(0.002)\end{array}$ & $\begin{array}{l}-0.09 \\
(0.08)\end{array}$ & $\begin{array}{l}-0.10 \\
(0.006)\end{array}$ & $\begin{array}{l}-0.04 \\
(0.22)\end{array}$ \\
\hline \multicolumn{8}{|l|}{ Black Females $(n=329)$} \\
\hline Activity Counts per min & $\begin{array}{l}0.02 \\
(0.71)\end{array}$ & $\begin{array}{l}0.08 \\
(0.18)\end{array}$ & $\begin{array}{l}-0.03 \\
(0.61)\end{array}$ & $\begin{array}{l}0.05 \\
(0.40)\end{array}$ & $\begin{array}{l}-0.19 \\
(0.02)\end{array}$ & $\begin{array}{l}-0.02 \\
(0.76)\end{array}$ & $\begin{array}{l}-0.15 \\
(0.008)\end{array}$ \\
\hline $\begin{array}{l}\text { Mod \& Vig Activity (min in 1-min } \\
\text { bouts) }\end{array}$ & $\begin{array}{l}-0.008 \\
(0.88)\end{array}$ & $\begin{array}{l}0.02 \\
(0.76)\end{array}$ & $\begin{array}{l}0.04 \\
(0.45)\end{array}$ & $\begin{array}{l}0.08 \\
(0.15)\end{array}$ & $\begin{array}{l}-0.159 \\
(0.05)\end{array}$ & $\begin{array}{l}-0.01 \\
(0.83)\end{array}$ & $\begin{array}{l}-0.08 \\
(0.13)\end{array}$ \\
\hline \multicolumn{8}{|l|}{$\begin{array}{l}\text { Mexican-American Females }(\mathrm{n}= \\
360 \text { ) }\end{array}$} \\
\hline Activity Counts per min & $\begin{array}{l}-0.04 \\
(0.44)\end{array}$ & $\begin{array}{l}-0.08 \\
(0.15)\end{array}$ & $\begin{array}{l}-0.04 \\
(0.40)\end{array}$ & $\begin{array}{l}0.04 \\
(0.48)\end{array}$ & $\begin{array}{l}-0.04 \\
(0.63)\end{array}$ & $\begin{array}{l}-0.13 \\
(0.01)\end{array}$ & $\begin{array}{l}-0.06 \\
(0.26)\end{array}$ \\
\hline $\begin{array}{l}\text { Mod \& Vig Activity (min in 1-min } \\
\text { bouts) }\end{array}$ & $\begin{array}{l}-0.05 \\
(0.38)\end{array}$ & $\begin{array}{l}-0.05 \\
(0.38)\end{array}$ & $\begin{array}{l}0.01 \\
(0.82)\end{array}$ & $\begin{array}{l}0.10 \\
(0.05)\end{array}$ & $\begin{array}{l}-0.10 \\
(0.22)\end{array}$ & $\begin{array}{l}-0.12 \\
(0.03)\end{array}$ & $\begin{array}{l}-0.07 \\
(0.17)\end{array}$ \\
\hline
\end{tabular}

*Adjusted for age and BMI.

** Plasma glucose concentration adjusted by fasting sampling weights. Plasma glucose sample sizes: $n=771$ white, $n=306$ black, $n=370$ Mexican American, $n=1447$ total sample. 
Table 6 Partial Correlation Coefficients (P-value) Physical Activity Monitor Measures and BMI, Overweight and Obesity* by Gender-Race/Ethnic Groups - NHANES 2003-2006, ages 20-65 y $(n=3,370)$

\begin{tabular}{|c|c|c|c|}
\hline Variable & $\begin{array}{l}\text { Body Mass } \\
\text { Index }\end{array}$ & Overweight & Obesity \\
\hline \multicolumn{4}{|l|}{ Total Sample $(n=3,370)$} \\
\hline Activity Counts per min & $\begin{array}{l}-0.16 \\
(<0.001)\end{array}$ & $\begin{array}{c}0.07 \\
(<0.001)\end{array}$ & $\begin{array}{l}-0.15 \\
(<0.001)\end{array}$ \\
\hline $\begin{array}{l}\text { Mod \& Vig Activity (min/d in 1- } \\
\text { min bouts) }\end{array}$ & $\begin{array}{l}-0.18 \\
(<0.001)\end{array}$ & $\begin{array}{c}0.10 \\
(<0.001)\end{array}$ & $\begin{array}{c}-0.18 \\
(<0.001)\end{array}$ \\
\hline \multicolumn{4}{|l|}{ White Males $(n=926)$} \\
\hline Activity Counts per min & $\begin{array}{l}-0.18 \\
(<0.001)\end{array}$ & $\begin{array}{c}0.05 \\
(0.12)\end{array}$ & $\begin{array}{l}-0.16 \\
(<0.001)\end{array}$ \\
\hline $\begin{array}{l}\text { Mod \& Vig Activity (min/d in 1- } \\
\text { min bouts) }\end{array}$ & $\begin{array}{c}-0.19 \\
(<0.001)\end{array}$ & $\begin{array}{c}0.09 \\
(0.006)\end{array}$ & $\begin{array}{l}-0.20 \\
(<0.001)\end{array}$ \\
\hline \multicolumn{4}{|l|}{ Black Males $(n=386)$} \\
\hline Activity Counts per min & $\begin{array}{l}-0.15 \\
(0.003)\end{array}$ & $\begin{array}{c}0.05 \\
(0.37)\end{array}$ & $\begin{array}{l}-0.10 \\
(0.06)\end{array}$ \\
\hline $\begin{array}{l}\text { Mod \& Vig Activity (min/d in 1- } \\
\text { min bouts) }\end{array}$ & $\begin{array}{l}-0.162 \\
(0.001)\end{array}$ & $\begin{array}{c}0.021 \\
(0.682)\end{array}$ & $\begin{array}{l}-0.107 \\
(0.036)\end{array}$ \\
\hline \multicolumn{4}{|l|}{$\begin{array}{c}\text { Mexican-American Males }(n= \\
463)\end{array}$} \\
\hline Activity Counts per min & $\begin{array}{c}-0.21 \\
(<0.001)\end{array}$ & $\begin{array}{l}0.007 \\
(0.89)\end{array}$ & $\begin{array}{c}-0.16 \\
(<0.001)\end{array}$ \\
\hline $\begin{array}{l}\text { Mod \& Vig Activity (min/d in 1- } \\
\text { min bouts) }\end{array}$ & $\begin{array}{c}-0.23 \\
(<0.001)\end{array}$ & $\begin{array}{l}0.004 \\
(0.94)\end{array}$ & $\begin{array}{c}-0.17 \\
(<0.001)\end{array}$ \\
\hline \multicolumn{4}{|l|}{ White Females $(n=837)$} \\
\hline Activity Counts per min & $\begin{array}{c}-0.19 \\
(<0.001)\end{array}$ & $\begin{array}{l}0.008 \\
(0.83)\end{array}$ & $\begin{array}{l}-0.17 \\
(<0.001)\end{array}$ \\
\hline $\begin{array}{l}\text { Mod \& Vig Activity (min/d in 1- } \\
\text { min bouts) }\end{array}$ & $\begin{array}{l}-0.25 \\
(<0.001)\end{array}$ & $\begin{array}{c}0.02 \\
(0.56)\end{array}$ & $\begin{array}{l}-0.22 \\
(<0.001)\end{array}$ \\
\hline \multicolumn{4}{|l|}{ Black Females $(n=375)$} \\
\hline Activity Counts per min & $\begin{array}{l}-0.06 \\
(0.27)\end{array}$ & $\begin{array}{c}0.04 \\
(0.45)\end{array}$ & $\begin{array}{l}-0.05 \\
(0.39)\end{array}$ \\
\hline $\begin{array}{l}\text { Mod \& Vig Activity (min/d in 1- } \\
\text { min bouts) }\end{array}$ & $\begin{array}{l}-0.14 \\
(0.007)\end{array}$ & $\begin{array}{c}0.08 \\
(0.11)\end{array}$ & $\begin{array}{l}-0.15 \\
(0.003)\end{array}$ \\
\hline \multicolumn{4}{|l|}{$\begin{array}{c}\text { Mexican-American Females ( } \mathrm{n} \\
=383 \text { ) }\end{array}$} \\
\hline Activity Counts per min & $\begin{array}{c}0.02 \\
(0.72)\end{array}$ & $\begin{array}{c}0.10 \\
(0.05)\end{array}$ & $\begin{array}{c}0.03 \\
(0.60)\end{array}$ \\
\hline $\begin{array}{l}\text { Mod \& Vig Activity (min/d in 1- } \\
\text { min bouts) }\end{array}$ & $\begin{array}{l}-0.08 \\
(0.10)\end{array}$ & $\begin{array}{c}0.06 \\
(0.28)\end{array}$ & $\begin{array}{l}-0.06 \\
(0.29)\end{array}$ \\
\hline
\end{tabular}

*Adjusted for age.

therefore replication of these relationships makes it is reasonable to assert that the accelerometer data from NHANES are capturing the physiologic benefit associated with increasing levels of physical activity. Admittedly this validation is indirect, and additional evidence must be sought in external studies which used similar methods. Objective measurement of energy expenditure has only become feasible in the last two decades, and few of the available studies include representative population samples $[17,18]$, therefore we know of no other studies bearing directly on this question. Methodological studies suggest that activity estimates from questionnaires are only correlated at approximately 0.2 with
DLW, generally viewed as the most accurate approach [34]. Activity monitors, on the other hand, have been shown to correlate on average at 0.5-0.6 with energy expenditure in activity $[14,35,36]$, representing a substantial increase in precision.

The critical question for these NHANES data, however, is not the degree to which accelerometry places individuals in the correct rank order of increasing activity, but whether the absolute amount of activity is being measured more accurately than by questionnaire. A recent review examined mean differences between estimates from DLW vs. questionnaire in 20 studies [34]. These studies were extremely heterogeneous in terms of sample size, type of participants and the questionnaire and, not surprisingly, the results were highly inconsistent; questionnaires overestimated energy expenditure by $1,000 \mathrm{kcal} /$ day in some instances and under-estimated by $400 \mathrm{kcal} /$ day in others [34]. A similarly heterogeneous literature exists on the concordance between accelerometry and DLW [14]. Contrary to questionnaires, accelerometry slightly under-estimated total expenditure in all but one report, and mean differences tended to be much smaller - in the range of $100-200$ $\mathrm{kcal} /$ day, or about $15-25 \%$ of physical activity expenditure. A second comprehensive review summarized the concordance between accelerometry and questionnaires in 47 validation studies [37]. On average, questionnaires recorded $44 \%$ more daily energy expenditure than did activity monitors. This second review also found that the degree of heterogeneity in the comparison of questionnaires with DLW was so great that no conclusions were possible, although there was an indication that the discrepancy was larger for women than men [37]. It must be recognized that the individual studies reviewed used a variety of instruments, each applying a different algorithm to generate caloric expenditure from activity counts, and they may not be directly comparable to the instrument used in NHANES. In general, however, it seems reasonable to conclude that questionnaires are subject to widely varying bias, most often leading to large over-estimates, while accelerometry has a far smaller, contrary tendency to under-estimation. This evidence would suggest that true expenditure among NHANES participants is closer to the accelerometry estimates, although somewhat higher. Nonetheless, even when applying a threshold of counts per minute that was only $30 \%$ of the standard set by direct calorimetry relatively few individuals met the guidelines.

Accelerometry is of course subject to potential biases. For example, cycling or activities that require weight bearing will not be adequately captured, although these are infrequent in the general population. Likewise the device is not worn while swimming. Artifactual increases in counts can also occur as a result of external sources 
of motion, such as riding in a vehicle. Artifact is a particularly important bias for these data since the vast majority of activity was recorded in episodes lasting only 1 minute. These short bursts are unlikely to represent intentional efforts to accumulate fitness-inducing exercise or physically demanding tasks at work of the type that would be captured by questionnaires. In fact, perhaps the most robust conclusion from this survey is that very few Americans engage in sustained activity, such as jogging or long walks, on a frequent basis. Likewise, in an on-going multi-national survey we have also observed a very low frequency of 10-minute bouts of activity in all 5 study populations (A. Luke, unpublished data). Clearly a more detailed analysis of questionnaire data in concert with accelerometry, and preferably DLW, will be required to resolve these questions.

In addition to the associations with metabolic risk factors, significant but quantitatively weak negative associations exist between the activity measures and BMI and obesity. Likewise, after accounting for BMI, the association with CVD risk factors was substantially weakened, highlighting the confounding that would be expected among these variables. The activity-BMI relationship cannot be considered causal, however, since these data are cross-sectional. Causality could be operating in the opposite direction or in both directions simultaneously. In fact, whether increased activity prevents weight gain is a contentious question. Despite the widely held perception that low levels of energy expenditure in activity is an important risk factor for obesity, prospective data do not support this view $[18,38]$. Randomized trials, where activity levels are rigorously measured and no attempt is made to restrict calories, likewise show that even substantial increases in energy expenditure in exercise do not result in weight loss because of compensatory increases in intake $[39,40]$. We conclude, therefore, that the associations observed in the NHANES data presented here between activity and relative weight are spurious - i.e., the direction of the causality is most likely from obesity to lower activity.

Previous analyses of the NHANES activity monitoring data have noted a similar outcome as reported here with regard to levels of activity for the US population and the association with obesity [13,15,41-44]. Troiano et al. [15] and Metzger et al. [13] reported a slightly higher proportion of the US population meeting the current physical activity guidelines than our estimate (i.e., 5\%). Metzger et al. used the data to define 5 classes of physical activity, including two classes of very low activity. The combined physical activity level of these 2 classes was less than 25 min of moderate/vigorous physical activity per day and represented almost $79 \%$ of the US population [13].

One of the challenges for activity assessment by accelerometry has been the choice of appropriate summary measures. Multiple alternative measures have been used and the results are often difficult to interpret or compare across studies [45-47]. After detailed preliminary analyses we chose three basic metrics - activity counts per minute and time spent in either vigorous or moderate activity. As noted, the 1-minute bouts are subject to over-estimation of activity across the day due to instability of the monitor The 10-minute bouts are potentially meaningful with regard to health benefits, but may not be capturing the true activity patterns of Americans and 2- or 3-minute bouts could yield different results. However, as shown in Figure 2, much less data will be available with these cut-points. Using data from an on-going multi-country study, we estimated an intraclass correlation coefficient of 0.88 with six days of activity monitoring, indicating the NHANES data presented here with an average of 6 days, characterize the individual's activity patterns over the measurement period quite well (A. Luke, unpublished data).

\section{Conclusion}

These analyses of the NHANES physical activity monitor data demonstrate that the US population is sedentary to a degree well beyond what had previously been assumed. Questionnaires on activity, as in most attempts to assess health behaviors, are subject to a strong social desirability bias. Numerous examples exist in the public health literature on behaviors as disparate as smoking and sexual practices $[48,49]$ and it is somewhat surprising in fact that reported data on activity have been taken at face value for so long. Nonetheless the degree of discrepancy exceeds reasonable expectations and unrecognized methodological problems may exist with use of accelerometry in the general population. This detailed analysis of the NHANES results provides a starting point from which to address this important question. Research and surveillance in this vital area will continue to be of limited value until we have access to accurate objective methods of measurement.

\section{Acknowledgements}

The authors would like to thank Shiv Sundram for his assistance in creating figures for this manuscript. This manuscript and authors' contributions were funded in part by a grant from the National Institutes of Health (DK080763).

\section{Authors' contributions}

$A L, L R D$ and RSC participated in the design and coordination of the study and helped to draft the manuscript. GC and RD conducted the statistical analyses and helped to draft the manuscript. All authors read and approved the final manuscript.

\section{Competing interests}

The authors declare that they have no competing interests.

Received: 4 January 2011 Accepted: 25 May 2011

Published: 25 May 2011 


\section{References}

1. Ford ES, Ajani UA, Croft JB, Critchley JA, Labarthe DR, Kottke TE, Giles WH, Capewell S: Explaining the decrease in U.S. deaths from coronary disease, 1980-2000. N Engl J Med 2007, 356:2388-2398.

2. Lloyd-Jones D, Adams R, Carnethon M, De Simone G, Ferguson TB, Flegal K, Ford E, Furie K, Go A, Greenlund K, et al: Heart disease and stroke statistics-2009 update: a report from the American Heart Association Statistics Committee and Stroke Statistics Subcommittee. Circulation 2009, 119:480-486.

3. Healthy People 2010 Midcourse Review. U.S. Department of Health and Human Services, Office of Disease Prevention and Health Promotion. [http://www.healthypeople.gov/data/midcourse/]

4. Flegal KM, Carroll MD, Ogden CL, Curtin LR: Prevalence and trends in obesity among US adults, 1999-2008. JAMA 303:235-241.

5. Caballero B: The global epidemic of obesity: an overview. Epidemiol Rev 2007, 29:1-5

6. 2008 Physical Activity Guidelines for Americans. US Department of Health and Human Services. [http://www.health.gov/paguidelines/pdf/ paguide.pdf].

7. Website. US Department of Health and Human Services. Let's Move Campaign. Internet. 2010 [http://www.letsmove.gov/]

8. Hughes JP, McDowell MA, Brody DJ: Leisure-time physical activity among US adults 60 or more years of age: results from NHANES 1999-2004. J Phys Act Health 2008, 5:347-358.

9. King GA, Fitzhugh EC, Bassett DR Jr, McLaughlin JE, Strath SJ, Swartz AM, Thompson DL: Relationship of leisure-time physical activity and occupational activity to the prevalence of obesity. 2001, 25:606.

10. Bonnefoy M, Normand S, Pachiaudi C, Lacour JR, Laville M, Kostka T: Simultaneous validation of ten physical activity questionnaires in older men: a doubly labeled water study. J Am Geriatr Soc 2001, 49:28-35.

11. Trabulsi J, Schoeller DA: Evaluation of dietary assessment instruments against doubly labeled water, a biomarker of habitual energy intake. Am J Physiol Endocrinol Metab 2001, 281:E891-899.

12. Sex, Lies, and Social Science. The New York Review of Books. [http:// www.nybooks.com/articles/archives/1995/apr/20/sex-lies-and-social-science/ ].

13. Metzger JS, Catellier DJ, Evenson KR, Treuth MS, Rosamond WD, SiegaRiz AM: Patterns of objectively measured physical activity in the United States. Med Sci Sports Exerc 2008, 40:630-638.

14. Plasqui $G$, Westerterp KR: Physical activity assessment with accelerometers: an evaluation against doubly labeled water. Obesity (Silver Spring) 2007, 15:2371-2379.

15. Troiano RP, Berrigan D, Dodd KW, Masse LC, Tilert T, McDowell M: Physical activity in the United States measured by accelerometer. Med Sci Sports Exerc 2008, 40:181-188.

16. Schoeller DA, van Santen E: Measurement of energy expenditure in humans by doubly labeled water method. J Appl Physiol 1982, 53:955-959.

17. Tooze JA, Schoeller DA, Subar AF, Kipnis V, Schatzkin A, Troiano RP: Total daily energy expenditure among middle-aged men and women: the OPEN Study. Am J Clin Nutr 2007, 86:382-387

18. Ebersole KE, Dugas LR, Durazo-Arvizut RA, Adeyemo AA, Tayo BO, Omotade OO, Brieger WR, Schoeller DA, Cooper RS, Luke AH: Energy expenditure and adiposity in Nigerian and African-American women. Obesity (Silver Spring) 2008, 16:2148-2154.

19. Centers for Disease Control and Prevention. National Health and Nutrition Examination Survey. [http://www.cdc.gov/nchs/nhanes.htm].

20. Physician examination procedures manual. Centers for Disease Control and Prevention (CDC). National Center for Health Statistics (NCHS). National Health and Nutrition Examination Protocol. Hyattsville, MD: US Department of Health and Human Services, Centers for Disease Control and Prevention. [http://www.cdc.gov/nchs/data/nhanes/nhanes_05 06/PE. pdf].

21. National Health and Nutrition Examination Survey Lab Methods. Centers for Disease Control and Prevention (CDC). National Center for Health Statistics (NCHS). National Health and Nutrition Examination Protocol. Hyattsville, MD: US Department of Health and Human Services, Centers for Disease Control and Prevention. [http://www.cdc.gov/nchs/nhanes/ nhanes2005-2006/lab_methods_05_06.htm]

22. Anthropometry and physical activity monitor procedures manual. Centers for Disease Control and Prevention (CDC). National Center for Health Statistics (NCHS). National Health and Nutrition Examination
Protocol. Hyattsville, MD: US Department of Health and Human Services, Centers for Disease Control and Prevention. [http://www.cdc.gov/nchs/ data/nhanes/nhanes_05_06/BM.pdf].

23. Welk GJ, Schaben JA, Morrow JR, Jr : Reliability of accelerometry-based activity monitors: a generalizability study. Med Sci Sports Exerc 2004, 36:1637-1645.

24. Freedson PS, Melanson E, Sirard J: Calibration of the Computer Science and Applications, Inc. accelerometer. Med Sci Sports Exerc 1998, 30:777-781.

25. Fitzhugh EC, Thompson DL: Leisure-time walking and compliance with ACSM/AHA aerobic-related physical activity recommendations: 19992004 NHANES. J Phys Act Health 2009, 6:393-402

26. Seo DC, Li K: Leisure-time physical activity dose-response effects on obesity among US adults: results from the 1999-2006 National Health and Nutrition Examination Survey. J Epidemiol Community Health 64:426-431.

27. Churilla JR, Fitzhugh EC: Relationship between leisure-time physical activity and metabolic syndrome using varying definitions: 1999-2004 NHANES. Diab Vasc Dis Res 2009, 6:100-109.

28. Sisson SB, Camhi SM, Church TS, Martin CK, Tudor-Locke C, Bouchard C, Earnest CP, Smith SR, Newton RL Jr, Rankinen T, Katzmarzyk PT: Leisure time sedentary behavior, occupational/domestic physical activity, and metabolic syndrome in U.S. men and women. Metab Syndr Relat Disord 2009, 7:529-536.

29. Klesges LM, Baranowski T, Beech B, Cullen K, Murray DM, Rochon J, Pratt C: Social desirability bias in self-reported dietary, physical activity and weight concerns measures in 8- to 10-year-old African-American girls: results from the Girls Health Enrichment Multisite Studies (GEMS). Prev Med 2004, 38(Suppl):S78-87.

30. Adams SA, Matthews CE, Ebbeling CB, Moore CG, Cunningham JE, Fulton J, Hebert JR: The effect of social desirability and social approval on selfreports of physical activity. Am J Epidemiol 2005, 161:389-398.

31. Banda JA, Clouston K, Sui X, Hooker SP, Lee CD, Blair SN: Protective health factors and incident hypertension in men. Am J Hypertens 23:599-605.

32. Lee CD, Sui X, Blair SN: Combined effects of cardiorespiratory fitness, not smoking, and normal waist girth on morbidity and mortality in men. Arch Intern Med 2009, 169:2096-2101.

33. Hooker SP, Sui X, Colabianchi N, Vena J, Laditka J, LaMonte MJ, Blair SN: Cardiorespiratory fitness as a predictor of fatal and nonfatal stroke in asymptomatic women and men. Stroke 2008, 39:2950-2957.

34. Neilson HK, Robson PJ, Friedenreich CM, Csizmadi I: Estimating activity energy expenditure: how valid are physical activity questionnaires? Am J Clin Nutr 2008, 87:279-291.

35. Bouten CV, Verboeket-van de Venne WP, Westerterp KR, Verduin M, Janssen JD: Daily physical activity assessment: comparison between movement registration and doubly labeled water. J Appl Physiol 1996, 81:1019-1026.

36. Hoos MB, Plasqui G, Gerver WJ, Westerterp KR: Physical activity level measured by doubly labeled water and accelerometry in children. Eur J Appl Physiol 2003, 89:624-626.

37. Prince SA, Adamo KB, Hamel ME, Hardt J, Gorber SC, Tremblay M: A comparison of direct versus self-report measures for assessing physical activity in adults: a systematic review. Int J Behav Nutr Phys Act 2008, 5:56.

38. Ferro-Luzzi A, Martino L: Obesity and Physical Activity. In Ciba Foundation Symposium 201: The Origins and Consequences of Obesity. Edited by: Chadwick DJ, Cardew G. New York: John Wiley 1996:207-227.

39. Church TS, Earnest CP, Skinner JS, Blair SN: Effects of different doses of physical activity on cardiorespiratory fitness among sedentary, overweight or obese postmenopausal women with elevated blood pressure: a randomized controlled trial. JAMA 2007, 297:2081-2091.

40. Dunn AL, Marcus BH, Kampert JB, Garcia ME, Kohl HW, Blair SN: Comparison of lifestyle and structured interventions to increase physical activity and cardiorespiratory fitness: a randomized trial. JAMA 1999, 281:327-334

41. Hagstromer M, Troiano RP, Sjostrom M, Berrigan D: Levels and patterns of objectively assessed physical activity-a comparison between Sweden and the United States. Am J Epidemio/ 171:1055-1064

42. Lynch BM, Dunstan DW, Healy GN, Winkler E, Eakin E, Owen N: Objectively measured physical activity and sedentary time of breast cancer survivors, and associations with adiposity: findings from NHANES (20032006). Cancer Causes Control 21:283-288. 
43. Hawkins MS, Storti KL, Richardson CR, King WC, Strath SJ, Holleman RG, Kriska AM: Objectively measured physical activity of USA adults by sex, age, and racial/ethnic groups: a cross-sectional study. Int I Behav Nutr Phys Act 2009, 6:31.

44. Matthews CE, Chen KY, Freedson PS, Buchowski MS, Beech BM, Pate RR, Troiano RP: Amount of time spent in sedentary behaviors in the United States, 2003-2004. Am J Epidemiol 2008, 167:875-881.

45. Kozey SL, Lyden K, Howe CA, Staudenmayer JW, Freedson PS Accelerometer Output and MET Values of Common Physical Activities. Med Sci Sports Exerc.

46. Ham SA, Reis JP, Strath SJ, Dubose KD, Ainsworth BE: Discrepancies between methods of identifying objectively determined physical activity. Med Sci Sports Exerc 2007, 39:52-58.

47. Nilsson A, Brage S, Riddoch C, Anderssen SA, Sardinha LB, Wedderkopp N, Andersen $L B$, Ekelund $U$ : Comparison of equations for predicting energy expenditure from accelerometer counts in children. Scand J Med Sci Sports 2008, 18:643-650.

48. Messeri PA, Allen JA, Mowery PD, Healton CG, Haviland ML, Gable JM, Pedrazzani SD: Do tobacco countermarketing campaigns increase adolescent under-reporting of smoking? Addict Behav 2007, 32:1532-1536.

49. Stuart GS, Grimes DA: Social desirability bias in family planning studies: a neglected problem. Contraception 2009, 80:108-112.

\section{Pre-publication history}

The pre-publication history for this paper can be accessed here: http://www.biomedcentral.com/1471-2458/11/387/prepub

doi:10.1186/1471-2458-11-387

Cite this article as: Luke et al:: Assessing Physical Activity and its Relationship to Cardiovascular Risk Factors: NHANES 2003-2006. BMC

Public Health 2011 11:387.

\section{Submit your next manuscript to BioMed Central and take full advantage of:}

- Convenient online submission

- Thorough peer review

- No space constraints or color figure charges

- Immediate publication on acceptance

- Inclusion in PubMed, CAS, Scopus and Google Scholar

- Research which is freely available for redistribution

Submit your manuscript at www.biomedcentral.com/submit 